\title{
Response of Outdoor Thermal Environment to Small Changes in Three-Dimensional Urban Morphology - a Case Study of Adding Elevators to a Residential Quarter in Xuzhou City, China
}

\author{
Hongxuan Zhou, Guixin Tao, Biao Ge, Xinye Yan, Jing Sun* \\ School of Architecture and Design, China University of Mining and Technology, \\ Xuzhou, Jiangsu 221116, PR China
}

Received: 1 June 2020

Accepted: 27 November 2020

\begin{abstract}
Three-dimensional urban morphology plays a role in adjusting the outdoor thermal environment while the effects of little variation in shape on outdoor thermal environment are still not evaluated. In addition, the renovation for senior people is getting more attention in China, which could be developed by installing elevators in old residential quarters. However, the evaluation of installing elevators in the perspective of outdoor thermal environment remains rare. Based on these two issues, 5 different parameters describing the three-dimensional urban morphology were chosen to simulate 4 scenarios and to analyze. Based on the results of one-way ANOVA and stepwise regression, installing elevator changed the three-dimensional shape of residential quarter, but the variation was less than $7 \%$; temperature $\left(\mathrm{T}_{\mathrm{a}}\right)$, mean radiation temperature (MRT), wind velocity (WV) and predictive mean vote (PMV) changed a little consequently, leading to very limited impacts on outdoor thermal qualities. The pattern of outdoor thermal environment slightly changed when installing elevators in the residential quarter, especially in the situation at night (no solar radiation). From the overall perspective of outdoor thermal environment evaluation, adding elevators in residential quarter has little effect on the threedimensional urban morphology and outdoor thermal environment.
\end{abstract}

Keywords: three-dimensional spatial urban structure, urban thermal environment, old community, aging people, building renovation

*e-mail: snowyjing83@163.com 


\section{Introduction}

\section{Impact of Outdoor Thermal Environment by Three-Dimensional Urban Morphology}

As one of the factors affecting residents' life, outdoor thermal environment is particularly important for the quality of life for urban residents. In recent decades, due to the extremely hot weather events superposed by global warming and urban heat island effect, many scholars have begun to do the research of the connection between outdoor thermal environment and threedimensional urban morphology which affected urban climate in some cases [1]. In some researches, extracted three-dimensional urban morphology indicators used to connect with outdoor thermal environment, the common ones including sky view factor ( $\Psi_{\mathrm{SKY}}$, the ratio of the visible area of the sky between buildings [2]) and aspect ratio $\left(\lambda_{\mathrm{s}}\right.$, calculated with the sum of building heights divides the distance between two buildings in a street canyon). Besides, building density $\left(\lambda_{\mathrm{p}}\right)$, floor area ratio $\left(\lambda_{\text {floor }}\right)$, and complete aspect ratio $\left(\lambda_{C}\right)$ are also important indicators that present urban morphology (all three-dimensional urban morphology indicators are introduced in section Calculation of Morphology Parameters).

As an important indicator in representing urban morphology and spatial canopy structure, $\Psi_{\text {SKY }}$ linked with outdoor thermal comfort and urban heat island effect [2, 3]. It Influenced the absorption of solar radiation inside the city and the restraint of long-wave radiation between urban structures. Low $\Psi_{\mathrm{SKY}}$ led to lower the temperatures during the day $[4,5]$, higher temperature at night $[6,7]$ the lower the surface temperature of the urban area [8], and the higher thermal comfort [9], and vice versa. There are fruitful research on relationship between $\Psi_{\text {SKY }}$ and the temperature, which were conducted in many cities, including Constantine [10], Hong Kong [11] and Montreal [12]. Besides, $\Psi_{\text {SKY }}$ was also found a significant influence on wind velocity, that $\Psi_{\text {SKY }}$ increased by $10 \%$ and wind velocity reduced by $8 \%$ [13]. Besides, $\lambda_{\mathrm{S}}$ and $\varphi_{\mathrm{c}}$ were also important factors that affect the urban thermal environment [14]. Compared to the other parameters $\left(\Psi_{\mathrm{SKY}}, \lambda_{\mathrm{s}}\right.$ and $\left.\varphi_{\mathrm{c}}\right)$, there were few studies focused on the relationship between other parameters, such as $\lambda_{\mathrm{p}}$ and $\lambda_{\text {floor }}$, and outdoor thermal environment. As a key urban form indicator that affects outdoor thermal environment [15]; $\lambda_{\mathrm{p}}$ is reasonably controlled, to regulate the air temperature and outdoor thermal comfort in cities [16]. Likewise, $\lambda_{\text {floor }}$ also affected outdoor thermal environment [17] , correlated with building density and the building height [18], showing negatively correlation with the air temperature at pedestrian height in the block [19]. As for $\lambda_{C}$ and other parameters, although they appear in the Urban Climate and they are strongly correlated with the formation and the mitigation of the urban heat island effect [1], there were few studies studying the impact of these parameters on the urban thermal eenvironment.

Aged population is becoming a serious social problem and their dwelling environment is going to be a matter of great concern in China. Hence, adding elevator on existing houses for the aged does not only need to solve related problems from the perspective of social science, but also a perspective of natural science [20]. In recent years, there are cases that elevators were installed outside existing buildings in many cities in China and this kind of demand is expected to keep growing in the future. The first existing residential elevator was located at Unit 3, Building 126 of Guandao residential quarter which started on March 28, 2019 and completed on May 21, 2019 in Xuzhou city, China. Meanwhile, other 68 units in this residential quarter passed the plan installing external elevator which would be carried out as quickly as possible to meet requirements of the building's renovation for the aged people. Although relevant regulations on adding elevators to existing residential buildings have been issued in many provinces in China, these regulations are mostly based on the impact of sunshine effect of additional facilities on the building but outdoor thermal environment issues were not involved. Based on the facts that the three-dimensional urban morphology of residential quarter would be changed slightly after installation of external elevators, it could be inferred that relevant outdoor thermal environment and ventilation conditions are going to change. On the basis of the global warming, urban heat island effect and the threat of high temperature facing elderly citizens, it is of significance to conduct such a study on the variation of outdoor thermal environments when external elevators were added to residential quarters.

\section{Research Objectives}

The usual method to add elevators to existing buildings in China is installing them outside of buildings. It is going to complicate the shape of buildings, as well as the three-dimensional urban morphology of the whole residential quarter. The parameters such as $\Psi_{\mathrm{SKY}}, \lambda_{\mathrm{P}}$ and $\lambda_{\text {floor }}$ are changed consequently, leading the variations of the outdoor thermal environment and ventilation in the residential quarter. However, the above mentioned influence from installation of outer elevators has been seldom studied. This study is exploring the influence of added elevator on the outdoor thermal environment in the residential area and the connection between little variation on three-dimensional urban morphology and outdoor thermal environment. Then from the perspective of outdoor thermal environment, it analyzes the feasibility of adding elevators on existing buildings to provide theoretical evidence on making and practicing of policies. On the one hand, how much the outdoor thermal environment varied when three-dimensional urban morphology slightly changed was studied. On the other hand, whether this kind 
of variation would have an impact on residents' life quality are also studied in this paper.

\section{Material and Methods}

\section{Study Area}

The research area is located in the Xuzhou City, China (between $116^{\circ} 22^{\prime} \mathrm{E}$ to $118^{\circ} 40^{\prime} \mathrm{E}$ and $33^{\circ} 43^{\prime} \mathrm{N}$ to $\left.34^{\circ} 58^{\prime} \mathrm{N}\right)$. It is about 210 kilometers long from east to west and 140 kilometers wide from north to south. Xuzhou has a temperate monsoon climate with four distinct seasons, not too hot in summer, not too cold in winter, annual temperature of $14^{\circ} \mathrm{C}$, annual sunshine hours of 2284-2495 hours, sunshine rate of $52 \%-57 \%$, annual frost free period of 200-220 days, annual average precipitation of $800-930 \mathrm{~mm}$, and rainy season accounted $56 \%$ precipitation in the whole year. From the above, the characteristic of Xuzhou climate could be summarized as follows: four distinct seasons, adequate light, moderate rainfall, and raining and hot during the same period.

Fig. 1 shows weather conditions in Xuzhou by month in 2018. Due to the summer was chosen for this study, we need to know the summer conditions in Xuzhou. The changes in the weather can be observed clearly that the highest air temperature occurs in July, followed by August; the average temperature in was higher than $28^{\circ} \mathrm{C}$ July and August in 2018, when the relative humidity was high in the two months as well. Wind velocity did not change too much throughout the year, all of which were greater than $1 \mathrm{~m} / \mathrm{s}$. By using data from Fig.1 and water vapor pressure principle, the absolute water content in air was highest during July and August, when the thermal comfort and the thermal environment quality got worse consequently.

Guandao residential quarter was chosen as the object of this study (Fig. 2a), built in 1990s, and would continue to provide shelters in next $5 \sim 6$ decades. In this residential quarter, aged population is going to increase continuously in the future. Hence, the requirements for installing elevators need to be solved urgently, which would not only improve the life quality of the aged people but also bring additional values to their houses. Most of the buildings were composed of brick and concrete with 6 stories. At back then, there was a regulation that the elevators were not allowed to be carried in the buildings with less than seven stories. Thus, no elevator appeared at the beginning of the construction of this residential quarter. As time flew by, life quality has been constantly improved and the demand using elevators in daily life is getting stronger than ever before. Installing elevators on existing buildings can not only bring convenience to users' life, but can also get rid of the urban renewal measure which needed massive reconstruction.

\section{Scenario Settings}

In this study, it is assumed that variation of threedimensional urban morphology (adding elevators outside existed buildings) was going to influence outdoor thermal environment. Hence, four scenarios were set to verify these effects.

Four simulation situations are input in ENVImet (V4.0 Bata, see section simulation) and listed as follows: scenario 1, a blank control, with no elevators in any buildings (Fig. 2c); scenario 2, a realistic one, with an elevator in a building in the middle of the area (Fig. 2d); scenario 3, a medium one, with 28 elevators in 10 buildings in the central area (Fig. 2e); scenario 4, the most one, with 114 elevators in every building outside of the cross area (Fig. 2f).

\section{Data Collection}

The three-dimensional urban morphology data were measured with a laser rangefinder (YP900H, sensor accuracy: $\pm 1 \mathrm{~m}$ ) on site, including building shapes (lengths, widths and heights), distance between buildings, elevator shapes, the road length and width. According to these data, digital model was built in ENVI-met software (V4.0 Bata) consequently.

Most meteorological data were gathered and stored with a weather station that was placed by the authors. Weather station sensors in this study collected air temperature (unit: $\mathrm{K}$, sensor accuracy: $0.2 \mathrm{~K}, 1.4 \mathrm{~m}$ above the ground surface) and relative humidity (sensor accuracy: 3\%, $1.4 \mathrm{~m}$ above the ground surface) while
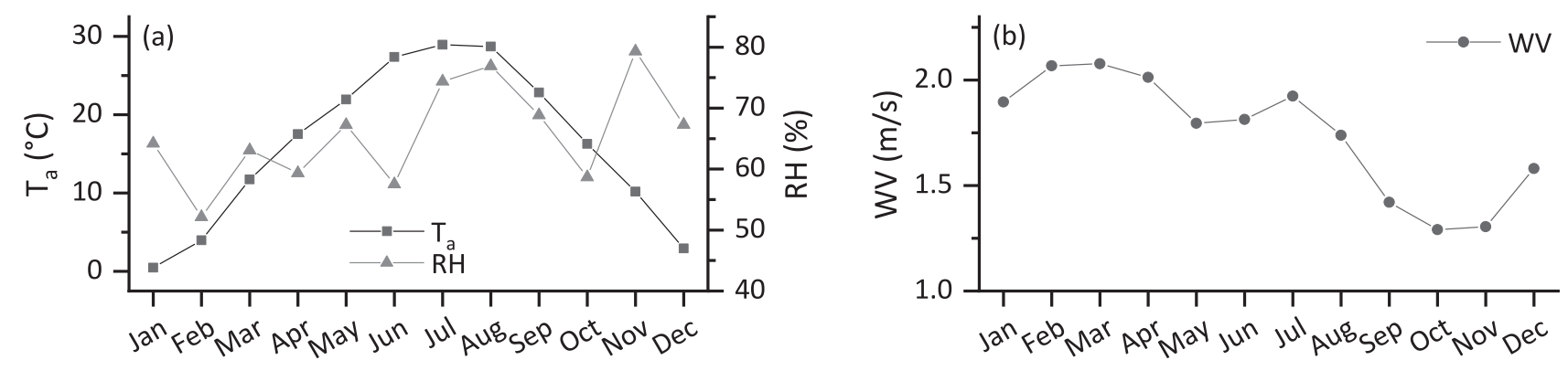

Month

Fig. 1. Atmosphere condition in 2018 in Xuzhou. 
the sampling interval was 1 minute and the logging interval was 10 minutes.

\section{Simulation}

All simulations were conducted in ENVI-met software (V4.0 Bata), which was developed by Michael Bruse and Heribert Fleer [21]. It is used to research microclimates and outdoor thermal environment in urban areas through computational fluid dynamics and basic models (formula and equation). For now, a great number of scholars around the world used this software and acquired achievements. It is a reliable software that is accurate enough to conduct urban thermal environment research.

In this study, using ENVI-met (version of 4.0 Bata), selected area's thermal environment was simulated before and after elevators installing in the existing residential buildings. The model area was processed in $230 \times 220 \times 25$ with a solution $3 \times 3 \times 2$ meters. Simulation started from 8:00 in the morning and lasted for 25 hours. The initial value was set as follows: at $2 \mathrm{~m}$, the temperature was $304.25 \mathrm{~K}$ and the relative humidity was $72 \%$; at $10 \mathrm{~m}$, wind velocity was $3 \mathrm{~m} / \mathrm{s}$ and the wind direction was $135^{\circ}$ southeast and at $2500 \mathrm{~m}$, the vapor content was $12 \mathrm{~g} / \mathrm{kg}$. The rest parameters were set as defaults. The simulation results contained air temperature at the height of $1.4 \mathrm{~m}\left(\mathrm{~T}_{\mathrm{a}},{ }^{\circ} \mathrm{C}\right)$, mean radiation temperature (MRT, ${ }^{\circ} \mathrm{C}$, defined as the uniform temperature of an imaginary environment), wind velocity $(\mathrm{WV}, \mathrm{m} / \mathrm{s})$, and predictive mean vote (PMV, a parameter to estimate thermal comfort [22], calculated with ENVI-met software). Time slices of these parameters, needed to compare,

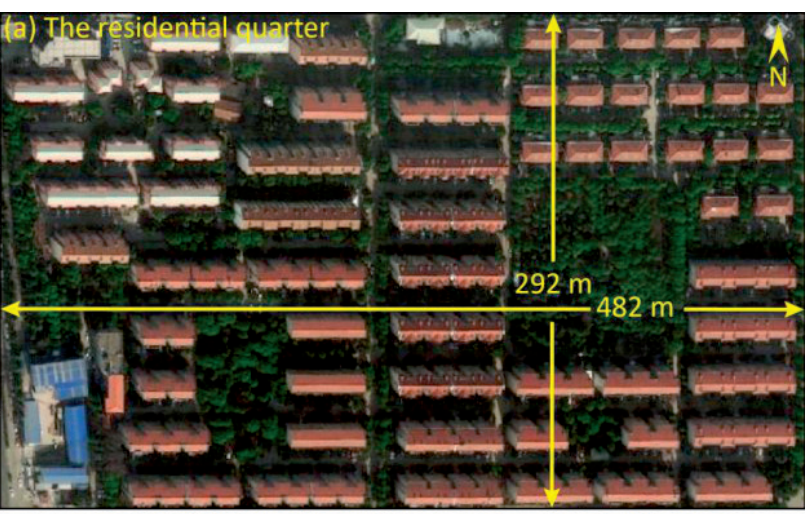

(c) Scenario 1
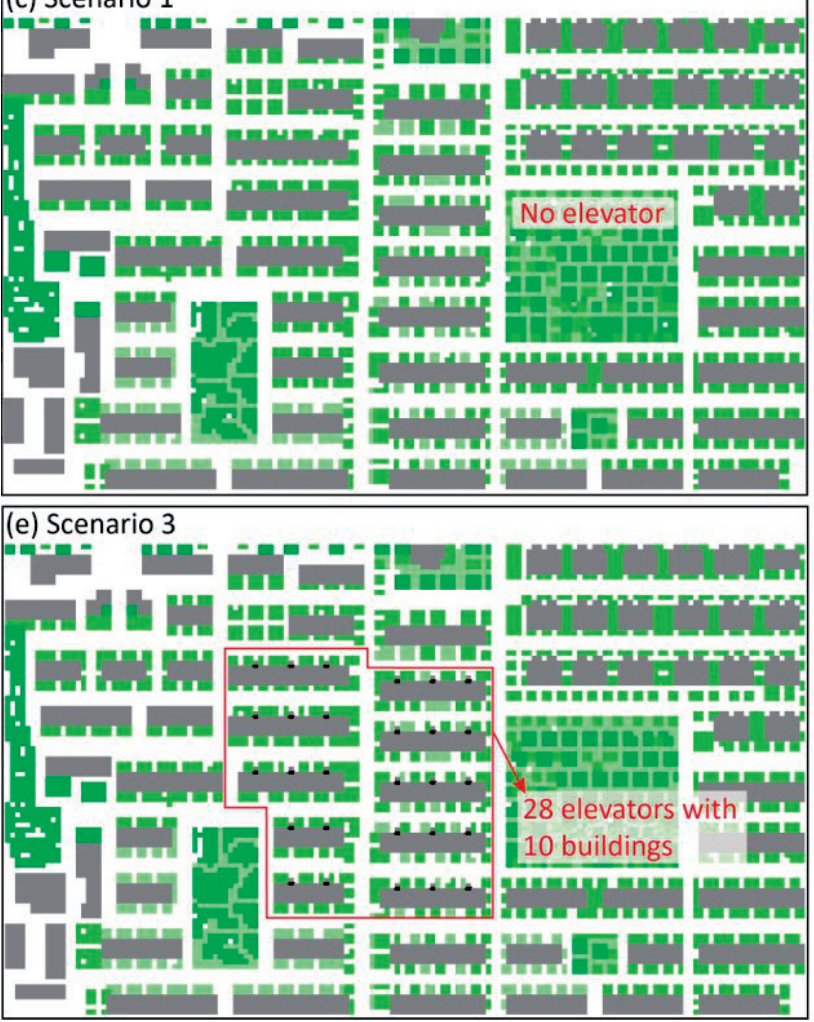
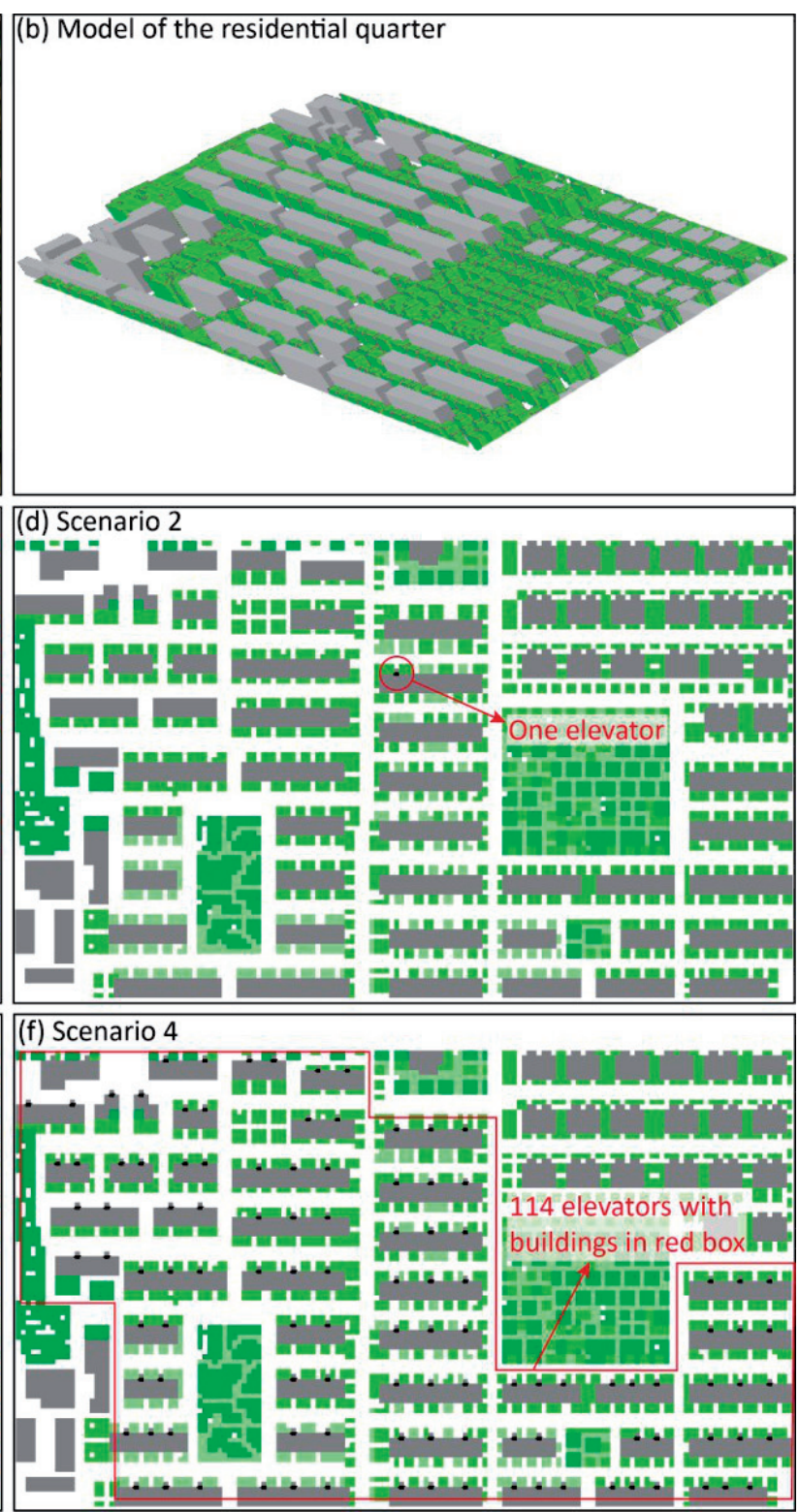

Fig. 2. Research area and scenario settings: a) satellite picture; b) digital model constructed by ENVI-met, grey for buildings and green for vegetation; c-f) four different scenarios. 
were chosen in 9:00, 12:00, 16:00, 20:00 and 6:00. The reason for choosing the five timestamp is that 9:00 is the commuting time, 12:00 hold the strongest solar radiation, 16:00 holds the highest air temperature, 20:00 is the time when residents take a walk after dinner and 6:00 is the time for sunrise.

\section{Model Verification}

Parameters are used to verify the accuracy of this model, such as root-mean-square error (RMSE), mean average error (MAE), mean absolute percentage error (MAPE), and the index of agreement (d). The calculation of these parameters is shown as formulas (1), (2), (3) and (4) [23, 24]. For those parameters, the more RMSE, MAE and MAPE tend to 0 and $\mathrm{d}$ tends to 1 , the more reliable the software is is $[25,26]$.

$$
\begin{gathered}
\text { RMSE }=\sqrt{\frac{\sum_{\mathrm{i}=1}^{\mathrm{n}}\left(\mathrm{x}_{\mathrm{i}}-\mathrm{y}_{\mathrm{i}}\right)^{2}}{\mathrm{n}}} \\
\text { MAE }=\frac{\sum_{\mathrm{i}=1}^{\mathrm{n}}\left|\mathrm{x}_{\mathrm{i}}-\mathrm{y}_{\mathrm{i}}\right|}{\mathrm{n}} \\
\mathrm{MAPE}=\frac{\sum_{\mathrm{i}=1}^{\mathrm{n}} \frac{\left|\mathrm{x}_{\mathrm{i}-} \mathrm{y}_{\mathrm{i}}\right|}{\mathrm{x}_{\mathrm{i}}}}{\mathrm{n}} \times 100 \% \\
\mathrm{~d}=1-\frac{\sum_{\mathrm{i}=1}^{\mathrm{n}}\left(\mathrm{y}_{\mathrm{i}}-\mathrm{x}_{\mathrm{i}}\right)^{2}}{\sum_{\mathrm{i}=1}^{\mathrm{n}}\left(\left|\mathrm{x}_{\mathrm{i}}-\overline{\mathrm{y}}\right|+\left|\mathrm{y}_{\mathrm{i}}-\overline{\mathrm{y}}\right|\right)^{2}}
\end{gathered}
$$

...where $x_{i}$ is simulation value and $y_{i}$ is collected value from the weather station, $\bar{x}$ is the mean value of the simulation, $\bar{y}$ is the mean value collected from the weather station, $\mathrm{n}$ is the total number of samples of $\mathrm{T}_{\mathrm{a}}$, which is 24 here.

\section{Calculation of Morphology Parameters}

The three-dimensional urban morphology of studied residential quarter is measured with several parameters including sky view factor $\left(\Psi_{\mathrm{SKY}}\right)$, building density $\left(\lambda_{\mathrm{P}}\right)$, floor area ratio $\left(\lambda_{\text {floor }}\right)$, and complete aspect ratio $\left(\lambda_{\mathrm{C}}\right)$, the ratio of building surface area to floor area $\left(\lambda_{\mathrm{SP}}\right)$. Except for $\Psi_{\text {SKY }}$ calculated in ENVI-met software, the rest of parameters was calculated based on formulas (5), (6), (7) [27] and (8).

$$
\begin{gathered}
\lambda_{\mathrm{p}}=\frac{\mathrm{A}_{\mathrm{p}}}{\mathrm{A}_{\mathrm{T}}} \\
\lambda_{\text {floor }}=\frac{\mathrm{A}_{\mathrm{F}}}{\mathrm{A}_{\mathrm{T}}}
\end{gathered}
$$

$$
\begin{array}{r}
\lambda_{\mathrm{C}}=\frac{\mathrm{A}_{\mathrm{C}}}{\mathrm{A}_{\mathrm{T}}}=\frac{\mathrm{A}_{\mathrm{w}}+\mathrm{A}_{\mathrm{R}}+\mathrm{A}_{\mathrm{G}}}{\mathrm{A}_{\mathrm{T}}} \\
\lambda_{\mathrm{SP}}=\frac{\mathrm{A}_{\mathrm{p}}}{\mathrm{A}_{\mathrm{w}}+\mathrm{A}_{\mathrm{R}}}
\end{array}
$$

...where $A_{p}$ is planning area of residential area, $A_{T}$ is total base area of buildings, $A_{f}$ is floor area, $A_{C}$ is the sum of the buildings' surface area and the floor area without buildings, $A_{W}$ is exterior wall area, $A_{R}$ is roof area, $A_{G}$ is the ground area without buildings.

\section{Data Processing}

The one-way ANOVA test in SPSS (V21.0) was used to analyze the differences between different thermal environment parameters at a different time under different scenario settings, with a confidence band of 95\%. Two examples are proposed to make it clearly: at 12:00, the temperature difference between four different scenarios; at 16:00, the difference of wind velocity between scenario 1 and scenario 2 .

Stepwise regression analysis in this study aims to find the correlation between morphology parameters and outdoor thermal parameters, judging which morphological parameters affect the outdoor thermal effect with slight changes by entering the regression equation. The F parameter in this analysis is 0.001-0.100. The stepwise regression analysis was implemented in SPSS (V21.0).

\section{Results and Discussion}

\section{Model Verification}

Statistical analysis was carried out on the simulated and monitored air temperature values (RMSE, MAE, MAPE and $d$ shown in Table 1). Simulated values showed some deviations with the measured values; under conditions of different cover types, d were very close to one, MAPE were very close to 0 , meaning the software was reliable. RMSE and MAE were near 1 , seeming greater too much than 0 , while these deviations were more in other studies [28]. Therefore, it indicated that the ENVI-met model has high accuracy for the thermal environment simulation results of hardened pavement and various vegetation

Table 1. Model verification parameters.

\begin{tabular}{|c|c|c|c|c|}
\hline Cover type & $\mathrm{d}$ & MAE & RMSE & MAPE \\
\hline Hardened pavement & 0.937 & 0.954 & 1.117 & $3.5 \%$ \\
\hline Grass & 0.796 & 1.099 & 1.303 & $4.6 \%$ \\
\hline Shrub + grass & 0.826 & 1.300 & 1.505 & $4.9 \%$ \\
\hline Trees + shrubs + grass & 0.974 & 0.753 & 0.927 & $2.8 \%$ \\
\hline
\end{tabular}


Table 2. Parameters of three-dimensional urban morphology in different scenarios.

\begin{tabular}{|c|c|c|c|c|c|c|}
\hline Scenario & $\begin{array}{c}\text { Number of } \\
\text { elevators }\end{array}$ & $\begin{array}{c}\Psi_{\mathrm{SKY}} \\
{[\text { variation (\%)] }}\end{array}$ & $\begin{array}{c}\lambda_{\mathrm{P}} \\
{[\text { variation (\%)] }}\end{array}$ & $\begin{array}{c}\lambda_{\text {floor }} \\
{[\text { variation (\%)] }}\end{array}$ & $\begin{array}{c}\lambda_{\mathrm{C}} \\
{[\text { variation (\%)] }}\end{array}$ & $\begin{array}{c}\lambda_{\mathrm{SP}} \\
{[\text { variation (\%)] }}\end{array}$ \\
\hline 1 & 0 & $0.1890[-0.00]$ & $0.2614[+0.00]$ & $1.3558[+0.00]$ & $1.8807[+0.00]$ & $4.3699[+0.00]$ \\
\hline 2 & 1 & $0.1889[-0.01]$ & $0.2615[+0.04]$ & $1.3566[+0.06]$ & $1.8827[+0.11]$ & $4.3753[+0.12]$ \\
\hline 3 & 28 & $0.1888[-0.07]$ & $0.2650[+1.38]$ & $1.3778[+1.62]$ & $1.9004[+1.05]$ & $4.3836[+0.31]$ \\
\hline 4 & 114 & $0.1846[-2.30]$ & $0.2763[+5.70]$ & $1.4455[+6.62]$ & $2.0031[+6.52]$ & $4.5765[+4.78]$ \\
\hline
\end{tabular}

combinations. Therefore, the software could be used in this study.

\section{The Difference of Three-Dimensional Urban Shape Parameters in Different Scenarios}

Comparing the four different scenarios, when adding different numbers of elevators in the residential quarter, $\Psi_{\mathrm{SKY}}$ gradually reduced and there were rising trends among $\lambda_{\text {floor }}, \lambda_{\mathrm{C}}, \lambda_{\mathrm{p}}$ and $\lambda_{\mathrm{SP}}$. However, the slight differences between the four scenarios limited the variation of these parameters. Extreme values appeared between scenario 1 and scenario 4 , meaning that $\Psi_{\text {SKY }}$ parameters reduced by $2.30 \% ; \lambda_{\mathrm{p}}, \lambda_{\text {floor }}, \lambda_{\mathrm{C}}$, and $\lambda_{\mathrm{Sp}}$ increased by $5.70 \%, 6.62 \%, 6.52 \%$ and $4.78 \%$ respectively. In contrast, comparing to scenario 1, scenario 2 is basically unchanged with all parameters; variation was less than $1 \%$. In scenario 3 , the threedimensional urban shape parameters variation is between scenario 2 and scenario 4. However, the quantity of adding elevators of scenario 3 is much less than scenario 4, leading to limited changes in parameters.

\section{Comparison of Outdoor Thermal Environment} Parameters between the Four Scenarios

Outdoor thermal environment parameters were compared between the four scenarios at five different timestamps (9:00, 12:00, 16:00, 20:00 and 6:00), shown in Table 3. The average $T_{a}$ differences between the four scenarios at the five moments were less than $0.1^{\circ} \mathrm{C}$. The average $\mathrm{T}_{\mathrm{a}}$ variation between the blank control group (with no elevators) and the scenario 2 group (with one elevator only) was less than $0.001^{\circ} \mathrm{C}$. Comparing with scenario 1 , the mean $\mathrm{T}_{\mathrm{a}}$ of scenario 3 decreased by $0.009,0.012,0.006,0.008$ and $0.012^{\circ} \mathrm{C}$ at five timestamps, respectively, which means the changed

Table 3. Outdoor thermal environment parameters of different scenarios.

\begin{tabular}{|c|c|c|c|c|c|c|}
\hline Item & Scenario & 9:00 & $12: 00$ & $16: 00$ & $20: 00$ & $6: 00$ \\
\hline \multirow{4}{*}{$\mathrm{T}_{\mathrm{a}}\left({ }^{\circ} \mathrm{C}\right)$} & Scenario 1 & $28.4359^{\mathrm{a}}$ & $31.8426^{\mathrm{a}}$ & $31.9517^{\mathrm{a}}$ & $28.4639^{\mathrm{a}}$ & $26.6840^{a}$ \\
\hline & Scenario 2 & $28.4355^{\mathrm{a}}$ & $31.8421^{\mathrm{a}}$ & $31.9513^{\mathrm{a}}$ & $28.4636^{\mathrm{a}}$ & $26.6836^{a}$ \\
\hline & Scenario 3 & $28.4269^{b}$ & $31.8311^{\mathrm{a}}$ & $31.9458^{\mathrm{a}}$ & $28.4560^{\mathrm{a}}$ & $26.6725^{b}$ \\
\hline & Scenario 4 & $28.3953^{\mathrm{c}}$ & $31.7855^{b}$ & $31.8848^{\mathrm{b}}$ & $28.4051^{\mathrm{b}}$ & $26.6614^{\mathrm{c}}$ \\
\hline \multirow{4}{*}{$\operatorname{MRT}\left({ }^{\circ} \mathrm{C}\right)$} & Scenario 1 & $43.9449^{a}$ & $47.8614^{\mathrm{a}}$ & $47.3307^{a}$ & $22.4267^{\mathrm{a}}$ & $20.6895^{a}$ \\
\hline & Scenario 2 & $43.9448^{\mathrm{a}}$ & $47.8572^{\mathrm{a}}$ & $47.3264^{\mathrm{a}}$ & $22.4259^{\mathrm{a}}$ & $20.6888^{a}$ \\
\hline & Scenario 3 & $43.9090^{\mathrm{a}}$ & $47.7679^{\mathrm{a}}$ & $47.3004^{a}$ & $22.3979^{a}$ & $20.6598^{a}$ \\
\hline & Scenario 4 & $43.5551^{b}$ & $47.4942^{b}$ & $46.6285^{b}$ & $22.3207^{b}$ & $20.6062^{b}$ \\
\hline \multirow{4}{*}{$\mathrm{WV}(\mathrm{m} / \mathrm{s})$} & Scenario 1 & $1.0435^{\mathrm{a}}$ & $1.0438^{\mathrm{a}}$ & $0.9936^{\mathrm{a}}$ & $0.8963^{\mathrm{a}}$ & $0.6833^{a}$ \\
\hline & Scenario 2 & $1.0435^{\mathrm{a}}$ & $1.0438^{\mathrm{a}}$ & $0.9936^{\mathrm{a}}$ & $0.8963^{\mathrm{a}}$ & $0.6834^{\mathrm{a}}$ \\
\hline & Scenario 3 & $1.0397^{\mathrm{a}}$ & $1.0397^{\mathrm{a}}$ & $0.9897^{\mathrm{a}}$ & $0.8931^{\mathrm{a}}$ & $0.6810^{\mathrm{a}}$ \\
\hline & Scenario 4 & $1.0054^{b}$ & $1.0096^{\mathrm{b}}$ & $0.9629^{b}$ & $0.8606^{b}$ & $0.6555^{b}$ \\
\hline \multirow{4}{*}{ PMV } & Scenario 1 & $1.7561^{\mathrm{a}}$ & $2.6233^{\mathrm{a}}$ & $2.6061^{\mathrm{a}}$ & $0.4737^{\mathrm{a}}$ & $0.1149^{\mathrm{a}}$ \\
\hline & Scenario 2 & $1.7560^{\mathrm{a}}$ & $2.6229^{a}$ & $2.6057^{\mathrm{a}}$ & $0.4736^{\mathrm{a}}$ & $0.1148^{\mathrm{a}}$ \\
\hline & Scenario 3 & $1.7534^{\mathrm{a}}$ & $2.6161^{\mathrm{a}}$ & $2.6038^{\mathrm{a}}$ & $0.4716^{\mathrm{a}}$ & $0.1119^{\mathrm{a}}$ \\
\hline & Scenario 4 & $1.7316^{b}$ & $2.5966^{b}$ & $2.5524^{\mathrm{b}}$ & $0.4629^{b}$ & $0.1123^{\mathrm{a}}$ \\
\hline
\end{tabular}

Note: $\mathrm{a}, \mathrm{b}$ and $\mathrm{c}$ mean different group situation in one-way ANOVA. 
three-dimensional urban morphology in scenario 3 led to a very limited reduction in $\mathrm{T}_{\mathrm{a}}$. Hence, in this scenario, the $\mathrm{T}_{\mathrm{a}}$ in this residential quarter decreased by about $0.010^{\circ} \mathrm{C}$ among these moments. The average $\mathrm{T}_{\mathrm{a}}$ of scenario 4 was lower than scenario 1 , decreasing by $0.041,0.057,0.067,0.059$ and $0.023^{\circ} \mathrm{C}$ at the five timestamps, respectively. It could be concluded that mean $\mathrm{T}_{\mathrm{a}}$ variation from the installation of elevators was very limited when the greatest change was $0.067^{\circ} \mathrm{C}$ among the five moments. However, the results from the one-way ANOVA indicated scenario 4 is significantly different $(\mathrm{P}<0.05)$ from the other three groups at these five moments. While scenario 3 was only significantly different $(\mathrm{P}<0.05)$ from scenario 1 and 2 at 9:00 and 6:00 (in next day). There were no significant differences $(\mathrm{P}>0.05)$ between scenario 1 and scenario 2 in all situations. Due to the comparison among the four scenarios in this study, the increase of installing elevators led to the decrease of $\Psi_{\mathrm{SKY}}$, accompanied by the reduction of air temperature at all five timestamps, no matter in the daytime or at night, indicating that the three-dimensional urban morphology influenced air temperature. According to Yan's study in 2014 [7], however, increased $\Psi_{\text {SKY }}$ led to higher diurnal air temperature and lower nocturnal one, which was different from this study. The reason for that could be the statistical method; in this study each grid was accounted, while in other research the object could be several specific points. As for $\lambda_{\text {floor }}$, it is a key factor to influence air temperature, for example, 92.6 percent of the temperature difference in downtown Bangkok depends on $\lambda_{\text {floor }}$ [29]. Besides, high $\lambda_{\text {floor }}$ led to the increasing of surface temperature [30]; it was deduced high $\lambda_{\text {floor }}$ corresponded to high air temperature, which opposite to results in this study. This could be the height of buildings were different between the two studies. Comparing with $\Psi_{\mathrm{SKY}}$ and $\lambda_{\text {floor }}$, research on $\lambda_{\mathrm{C}}$ were relatively rare. Besides, as a body type coefficient used to describe a residential area, $\lambda_{\mathrm{SP}}$ was a new threedimensional urban morphology parameter proposed in this paper. $\lambda_{\mathrm{C}}$ and $\lambda_{\mathrm{SP}}$ also influenced air temperature to some extent.

Among these four scenarios, installing elevators changed three-dimensional urban morphology of the residential quarter had further effect on MRT. As shown in Table 3, the greatest differences between the four scenarios at the five different moments were found between scenario 1 and scenario 4 , contributing $0.39,0.37,0.70,0.11$ and $0.0^{\circ} \mathrm{C}$, respectively. However, little variation of MRT was found between scenario1, 2 and 3; comparing with scenario 1, the MRT decreased less than $0.005^{\circ} \mathrm{C}$ in scenario 2 and it contributed less than $0.01^{\circ} \mathrm{C}$ in scenario 3 . Results of the one-way ANOVA shows the MRT difference among scenarios 1 , 2 and 3 was not significant at the level of 0.05 , but there was significant difference $(\mathrm{P}<0.05)$ between scenario 4 and the other three scenarios. Hence, the urban three-dimensional shape changes caused by adding a sufficient number of elevators on existing buildings was able to affect MRT. Three-dimensional urban morphology directly affected MRT [31], such as $\Psi_{\mathrm{SKY}}$ [32], higher $\Psi_{\mathrm{SKY}}$ raised MRT [33], which was similar to the results in this study. Installing elevators led to the decrease of $\Psi_{\text {SKY }}$, accompanied by the reduction of MRT at all five timestamps. This phenomenon may be caused by the strong solar radiation brought by the high $\Psi_{\text {SKY }}$ [34] and low $\Psi_{\text {SKY }}$ value would limit the solar radiation at the ground level. Researches on the other threedimensional morphology parameters and MRT were little, but effects of these important parameters on MRT were not negligible, meaning changes of parameters $\left(\lambda_{\mathrm{P}}, \lambda_{\text {floor }}, \lambda_{\mathrm{C}}\right.$ and $\left.\lambda_{\mathrm{SP}}\right)$ affected the MRT in the residential quarter [35]. After the installation of elevators, the four parameters increased and the space in residential quarter was compacted and closed, accompanied by the low values of MRT. These results corresponded to other studies (the higher opening of residential quarter, the higher MRT [36]) to a high degree.

In terms of wind velocity, it changes as the number of elevators increases (Table 3). The wind velocity of scenario 4 is lower than that of scenario 1; the reduction was between $0.03-0.05 \mathrm{~m} / \mathrm{s}$. A similar situation was also found between scenario 3 and scenario 1; wind velocity was lower in scenario 3 than scenario 1 , but less than $0.01 \mathrm{~m} / \mathrm{s}$. It was basically the same of scenario 2 as scenario 1. Results of one-way ANOVA shows the wind velocity differences among scenarios 1, 2 and 3 were not significant $(\mathrm{P}>0.05)$, but there were significant differences $(\mathrm{P}<0.05)$ between scenario 4 and the other three scenarios. Hence, it could be concluded that wind velocity was not influenced in the condition of adding a few of elevators, but it will be significantly affected when the number of elevators increases to a certain extent. It means that there was a threshold of the threedimensional urban shape to determine whether the wind velocity was significantly affected or not. $\Psi_{\text {SKY }}$ affected the ventilation in cities [37]; lower $\Psi_{\text {SKY }}$ resulted in lower wind velocity [13], corresponding to results in this study. Although the three-dimensional urban morphology parameters and wind velocity varied within a narrow range, there was a positive correlation (at the level of 0.01 ) between them. In contrast, other threedimensional urban morphology parameters $\left(\lambda_{\mathrm{P}}, \lambda_{\text {floor }}\right.$, $\lambda_{\mathrm{C}}$ and $\lambda_{\mathrm{SP}}$ ) were negatively correlated to wind velocity. Urban ventilation was affected by $\lambda_{\mathrm{p}}$ [38], meaning high $\lambda_{\mathrm{p}}$ could decrease average wind velocity in cities [39], which was similar to results in this research at a high degree. As a key parameter of three-dimensional urban morphology, $\lambda_{\text {floor }}$ was found its correlation to urban pollution diffusion was not significant, via its indirect influence on wind speed [40]. Thus, it could be inferred that $\lambda_{\text {floor }}$ was not closely related to wind velocity. This inference corresponded with the results in this study that while $\lambda_{\text {floor }}$ correlated (at 0.01 level) with wind velocity at some timestamps and not at the other moments. Therefore, it was possible to consider that $\lambda_{\text {floor }}$ was not a key factor to influence wind velocity. 
Comparing with the three parameters, studies on $\lambda_{\mathrm{C}}$ and $\lambda_{\mathrm{SP}}$ remained relatively little. However, these two parameters correlated to wind velocity (at 0.01 level) at all five timestamps. Therefore, it could be inferred changes of three-dimensional urban morphology brought by installing elevators would not strongly affect wind velocity in the residential quarters. Hence, in the perspective of wind velocity, installing elevators on existing buildings was feasible.

As for PMV, the values were very close to each other among the four scenarios. As shown in Table 3, PMV decreased with the number of elevators increased at all timestamps, except at 6:00. PMV at 20:00 and 6:00 were close to zero, with the highest thermal comfort; at 9:00 were between 1 and 2, with the medium comfort; at 12:00 and 16:00 were more than 2, with the lowest thermal comfort among the five timestamps. The greatest difference of PMV value was found between scenario 1 and scenario 4; it varied between 0.01 and 0.05 in the five timestamps, while the difference between other scenarios was less than 0.001 . Although the PMV was very close between the four scenarios, one-way ANOVA analysis showed that there were significant differences $(\mathrm{P}<0.05)$ between scenario 4 and the other three scenarios at 9:00, 12:00, 16:00 and 20:00, but no significant difference $(\mathrm{P}>0.05)$ was found among the four scenarios at 6:00. Therefore, it indicated that installing enough elevators on existing buildings affected the outdoor thermal comfort by changing three-dimensional urban morphology. On the basis of the comparison among the four scenarios, there was a threshold of the three-dimensional urban morphology variation (between scenario 3 and scenario 4) to influence outdoor thermal comfort. Besides, the influence of the three-dimensional urban morphology variation changed with time at a diurnal scale. Outdoor thermal comfort depended on the accumulation of solar radiation, the three-dimensional urban morphology affects thermal comfort by changing the acquisition of solar radiation inside the residential quarter [14]. In some researches, $\Psi_{\mathrm{SKY}}$ was considered a key factor to influence thermal environment and had a positive correlation with physiologically equivalent temperature [41], meaning high $\Psi_{\text {SKY }}$ brought the high probability of physiologically equivalent temperature [42]. Consequently, high $\Psi_{\text {SKY }}$ value in hot summer decreased the thermal comfort and vice versa, which were consistent with the results in this study. In this research, with the increase of $\lambda_{\mathrm{p}}$, the thermal comfort tended to a comfortable range. It was different from other scholars' results that the area with the highest $\lambda_{\mathrm{p}}$ got the lowest thermal comfort [43]. Though $\lambda_{\mathrm{p}}$ had certain effect on thermal comfort [44]. The difference may be caused by the average height of buildings, not only by $\lambda_{\mathrm{p}}$. As for $\lambda_{\text {floor }}$, it did not enter the regression equation of PMV, which was consistent with results in other research, that $\lambda_{\text {floor }}$ had little to do with outdoor thermal environment [45].

\section{The Correlation between Three-Dimensional Urban Morphology and Outdoor Thermal Environment Parameters}

Using correlation analysis with a confidence band of $99 \%$ (to find the most relevant parameters), it was shown that the correlation coefficients were all greater than 0.8 (except for the one containing PMV at 6:00) in Table 4. As given in Table 4, $\Psi_{\mathrm{SKY}}$ and outdoor thermal environment parameters were positively correlated, the other parameters $\left(\lambda_{\mathrm{P}}, \lambda_{\text {floor }}, \lambda_{\mathrm{C}}, \lambda_{\mathrm{SP}}\right)$ were negatively correlated with outdoor thermal environment parameters. For $\mathrm{T}_{\mathrm{a}}, \mathrm{MRT}$ and PMV, $\lambda_{\mathrm{C}}$ and $\lambda_{\mathrm{SP}}$ had the highest probability of significant correlations $(\mathrm{P}<0.01)$; for $\mathrm{WV}, \Psi_{\mathrm{SKY}}, \lambda_{\mathrm{C}}$ and $\lambda_{\mathrm{SP}}$ held the highest probability of

Table 4. Correlation coefficient between three-dimensional urban morphology and outdoor thermal parameters.

\begin{tabular}{|c|c|c|c|c|c|c|c|c|c|c|}
\hline Time & 9:00 & $12: 00$ & $16: 00$ & 20:00 & $6: 00$ & 9:00 & $12: 00$ & $16: 00$ & $20: 00$ & $6: 00$ \\
\hline & $\mathrm{T}_{\mathrm{a}}$ & $\mathrm{T}_{\mathrm{a}}$ & $\mathrm{T}_{\mathrm{a}}$ & $\mathrm{T}_{\mathrm{a}}$ & $\mathrm{T}_{\mathrm{a}}$ & MRT & MRT & MRT & MRT & MRT \\
\hline$\Psi_{\mathrm{SKY}}$ & 0.882 & 0.982 & 0.986 & $0.999^{*}$ & $0.995^{*}$ & 0.945 & $0.998^{*}$ & 0.975 & $1.000^{*}$ & 0.970 \\
\hline$\lambda_{\mathrm{p}}$ & -0.962 & $-1.000^{*}$ & $-0.999 *$ & -0.987 & $-0.994 *$ & $-0.993 *$ & -0.988 & $-1.000 *$ & -0.979 & $-1.000^{*}$ \\
\hline$\lambda_{\text {floor }}$ & -0.962 & $-1.000 *$ & $-0.999 *$ & -0.987 & $-0.994 *$ & $-0.993^{*}$ & -0.988 & $-1.000 *$ & -0.979 & $-1.000 *$ \\
\hline$\lambda_{\mathrm{C}}$ & -0.936 & $-0.998^{*}$ & $-0.999 *$ & $-0.997 *$ & $-0.999 *$ & -0.980 & $-0.997 *$ & $-0.996^{*}$ & $-0.992 *$ & $-0.994 *$ \\
\hline \multirow[t]{2}{*}{$\lambda_{\mathrm{SP}}$} & -0.935 & $-0.998^{*}$ & $-0.999 *$ & $-0.997 *$ & $-1.000^{*}$ & -0.979 & $-0.998 *$ & $-0.996^{*}$ & $-0.993 *$ & $-0.994 *$ \\
\hline & WV & WV & WV & WV & WV & PMV & PMV & PMV & PMV & PMV \\
\hline$\Psi_{\mathrm{SKY}}$ & $0.999 *$ & $0.998^{*}$ & $0.996^{*}$ & $0.995^{*}$ & $0.998^{*}$ & $0.997 *$ & 0.971 & $1.000 *$ & 0.987 & 0.513 \\
\hline$\lambda_{\mathrm{p}}$ & -0.987 & -0.989 & $-0.992 *$ & $-0.993 *$ & -0.988 & $-0.991 *$ & $-1.000^{*}$ & -0.979 & $-0.999 *$ & -0.685 \\
\hline$\lambda_{\text {floor }}$ & -0.987 & -0.989 & $-0.992 *$ & $-0.993 *$ & -0.988 & $-0.991 *$ & $-1.000 *$ & -0.979 & $-0.999 *$ & -0.685 \\
\hline$\lambda_{\mathrm{C}}$ & $-0.997 *$ & $-0.998 *$ & $-0.999 *$ & $-0.999 *$ & $-0.997^{*}$ & $-0.999 *$ & $-0.994 *$ & $-0.992 *$ & $-1.000 *$ & -0.623 \\
\hline$\lambda_{\mathrm{SP}}$ & $-0.997 *$ & $-0.998 *$ & $-0.999 *$ & $-0.999 *$ & $-0.997 *$ & $-0.999 *$ & $-0.994 *$ & $-0.993^{*}$ & $-0.999 *$ & -0.620 \\
\hline
\end{tabular}


significant correlation $(\mathrm{P}<0.01)$. Hence, the strongest correlation was found between $\lambda_{\mathrm{C}}$ and $\lambda_{\mathrm{SP}}$ and outdoor thermal environment parameters.

During the whole day, the significant correlation $(\mathrm{P}<0.01)$ frequency order is 16:00, 20:00, 12:00, 6:00 and 9:00. It means during the day when solar radiation is relatively strong, partial thermal environment could be adjusted by changing three-dimensional urban morphology, while after the sunset, there was a time lag in the adjustment. Hence, three-dimensional urban morphology played a corresponding role at 20:00, while after sunrise, the effect of three-dimensional urban morphology appeared weakest at 9:00. This could be the three-dimensional urban morphology regulated outdoor thermal environment in a passive mode, related to solar radiation. After sunrise, the passive regulation was disturbed.

\section{Three-Dimensional Urban Morphology Parameters Entered Stepwise Regression Equations}

According to the stepwise regression, although there were significant correlations among the five three-dimensional urban morphology parameters and outdoor thermal environment, the parameters entering into the stepwise regression equation were different at different timestamps (Table 5). The timestamp when the most parameters $\left(\Psi_{\mathrm{SKY}}, \lambda_{\mathrm{SP}}, \lambda_{\mathrm{P}}\right.$ and $\left.\lambda_{\mathrm{C}}\right)$ entered stepwise regression equations was 12:00, followed by 9:00 $\left(\lambda_{\text {floor }}, \lambda_{\mathrm{P}}\right)$, 16:00 $\left(\Psi_{\mathrm{SKY}}, \lambda_{\mathrm{SP}}\right)$ and 20:00 $\left(\lambda_{\mathrm{SP}}, \lambda_{\mathrm{P}}\right)$, and no three-dimensional urban morphology parameter entered stepwise regression equation at 6:00. According to results mentioned above, different three-dimensional urban morphology parameters played different roles at different timestamps during the daytime, while the roles of various three-dimensional urban morphology parameters weakened at night till the next morning. It is deduced that the influence of three-dimensional urban morphology parameters on the outdoor thermal environment was indirect and varies with the driving of some unknown factors, may be solar radiation.

\section{Thermal Comfort Difference between Scenario 1 and Scenario 4}

The largest difference in outdoor thermal environment was found between scenario 1 and scenario 4 in this study, comparison of PMV was conducted in these two situations at different moments. As shown in Fig. 3 (calculated by subtracting scenario 1 from scenario 4), a) PMV was lower in scenario 4 than that in scenario 1 at most grids, the opposite situation happens at very low probability at 9:00. The difference between the two scenarios varied from -2.56-1.69. Also, PMV fluctuated most at the grids near elevators. b) At 12:00, the differences of PMV fluctuated within -1.68 to 1.15 . Affected by installed elevators, PMV decreased most at the north of added elevators and it increased mostly near elevators, the dense building areas and greenery areas in particular (PMV decreased with shading effects of added elevators and increased with wind block due to installing elevators). c) the differences of PMV varied between -1.96 and 2.94 at 16:00. The low values were mostly concentrated on the north of the installed elevators within a small spatial scale (Fig. 3c) and the high values were mostly concentrated around the buildings accompanied by low values, which should be attributed to low wind velocity caused by elevators. d) At 20:00, the differences of PMV was narrowed at a small range between -0.25 and 0.28 . It was negative in the most of grids and the lowest values concentrated around elevators. High values of difference of PMV gathered around the buildings especially between two elevators and western areas to buildings. The reason for that could be elevators stabilized around outdoor thermal environment and they blocked the east wind so that the ventilation deteriorated at the west side of buildings. e) At 6:00, the differences of PMV was between -0.31 and 0.44 . The distribution of it was similar to that at 20:00 spatially. In this comparison between the scenario 1 and scenario 4, the southeastern area was improved most in this study, while the western and greenery areas were found increased PMV.

Comparing all the timestamps in Fig. 3, different attributions at different timestamps were deduced. The reduction of PMV between 9:00 and 16:00 was caused by shading effects of added elevators. While the solar radiation decreased to 0 at 20:00, when the decrease of PMV around elevators was mainly due to the continuation of the lower PMV in the shaded areas during the day and the contribution of wind. Similar reason for lower PMV at 6:00 was also attributed to the contribution of wind, which was influenced by installing elevators, due to solar radiation influenced the outdoor thermal environment at a low level. Therefore,

Table 5. Three-dimensional urban morphology parameters entering the stepwise regression.

\begin{tabular}{|c|c|c|c|c|c|}
\hline Outdoor thermal environment parameter & $9: 00$ & $12: 00$ & $16: 00$ & $20: 00$ & $6: 00$ \\
\hline $\mathrm{T}_{\mathrm{a}}$ & $\lambda_{\text {floor }}$ & $\lambda_{\mathrm{P}} \lambda_{\mathrm{C}}$ & - & $\lambda_{\mathrm{SP}}$ & - \\
\hline $\mathrm{MRT}$ & - & $\lambda_{\mathrm{P}}$ & $\psi_{\mathrm{SKY}}$ & $\lambda_{\mathrm{P}}$ & - \\
\hline $\mathrm{WV}$ & - & $\lambda_{\mathrm{SP}}$ & $\lambda_{\mathrm{SP}}$ & - & - \\
\hline $\mathrm{PMV}$ & $\lambda_{\mathrm{P}}$ & $\psi_{\mathrm{SKY}}$ & $\lambda_{\mathrm{SP}}$ & - & - \\
\hline
\end{tabular}

Note: - means no parameter is selected 

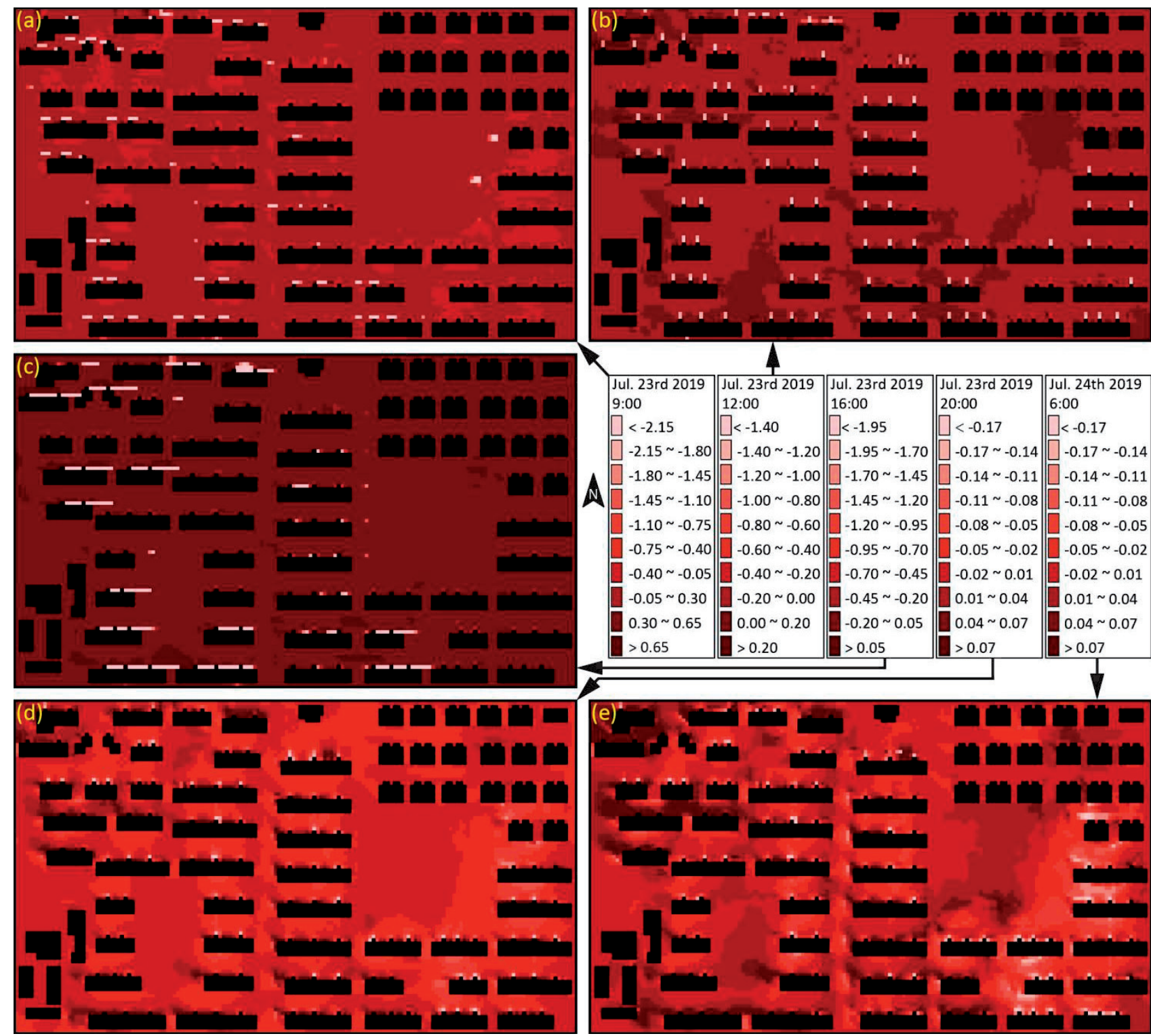

Fig. 3. Differences in outdoor thermal environment between scenario 1 and scenario 4 .

areas where PMV increased were mainly found between buildings and west side of them, excluding the effects of greenery.

\section{Conclusions}

In this study, four different scenarios (four schemes of installing elevator outside buildings) were simulated in ENVI-met software in summer in 2019 to figure out response of outdoor thermal environment to small changes in three-dimensional urban morphology. Results showed that the variation was limited within a small range. Maximal variations of variation of sky view factor $\left(\Psi_{\mathrm{SKY}}\right)$, building density $\left(\lambda_{\mathrm{P}}\right)$, floor area ratio $\left(\lambda_{\text {floor }}\right)$, complete aspect ratio $\left(\lambda_{\mathrm{C}}\right)$ and the ratio of building surface area to floor area $\left(\lambda_{\mathrm{SP}}\right)$ were $-2.30 \%$, $5.70 \%, 6.62 \%, 6.52 \%$ and $4.78 \%$, respectively. These three-dimensional urban morphology variations could affect the outdoor thermal environment, but within a small range. Adding elevators outside buildings could benefit the life convenience of aged people and also the outdoor thermal environment around buildings. But it could result in deteriorative outdoor thermal environment at adjacent greenspaces. Small changes of three-dimensional urban morphology would not significantly influence outdoor thermal environment, but enough added elevators could affect it. Based on this study, there have to be thresholds for three-dimensional urban morphology parameters to change outdoor thermal environment. However, it is taking too much simulation to obtain those thresholds, which is going to be studied in the next step. Through this research, those thresholds for $\Psi_{\mathrm{SKY}}, \lambda_{\mathrm{P}}, \lambda_{\text {floor }}, \lambda_{\mathrm{C}}$ were $-0.07 \% \sim-2.30 \%$, $1.38 \% \sim 5.70 \%, \quad 1.62 \% \sim 6.62 \%, \quad 1.05 \% \sim 6.52 \%$, and $0.31 \% \sim 4.78 \%$, respectively. All the mentioned threedimensional urban morphology parameters correlated to outdoor thermal environment, but their correlation 
changed with local time. Stepwise regressions showed that different three-dimensional morphology parameters entered regression equation at different timestamps, indicating that these parameters did not influence the outdoor thermal environment directly, but in an indirect way. Finally, the change of three-dimensional urban morphology after installing elevators would benefit some surroundings around the elevators and would do opposite effect to some specific areas. Hence, their advantages and disadvantages need to be fully assessed in future.

However, there is still room for the further improvement in this study. (1) Due to the limitation of the simulation software, the anthropogenic thermal parameters of elevators were not taken into account, which needs to be modified in the future. (2) Only situations in dog days were simulated, though representative, the coldness of winter is worth of studying in outdoor thermal environments which needs to be added in the future. (3) The remote influence of the little change of urban morphology on outdoor thermal environment in other areas is also a key point in the future. (4) Although the effect of installing elevators on the residential quarter were little from the perspective of outdoor thermal environment, other angles of view are needed, such as wind environment and air pollution. Only by fully evaluating the various impacts caused by changes of three-dimensional urban morphology in residential quarters can provide services for improving the quality of life for the elders and building a better living environment.

\section{Acknowledgements}

This research was funded by Natural Science Foundation of Jiangsu Province of China, grant number BK20170272, National Natural Science Foundation of China, grant number 51908544; Humanities and Social Science Research of Ministry of Education, China, grant number 19YJC760169, 18YJC760116; and the Fundamental Research Funds for the Central Universities, grant number 2017QNA28.

\section{Conflict of Interest}

The authors declare no conflict of interest.

\section{References}

1. OKE T., CANADA Initial guidance to obtain representative meteorological observations at urban sites. 2006.

2. OKE T.R. Canyon geometry and the nocturnal urban heat island: Comparison of scale model and field observations. Journal of Climatology. 1 (3), 237-, 1981.

3. EDUSSURIYA P., CHAN A.,YE A. Urban morphology and air quality in dense residential environments in
Hong Kong. Part I: District-level analysis. Atmospheric Environment. 45 (27), 4789, 2011.

4. ERELL E.,WILLIAMSON T. Intra-urban differences in canopy layer air temperature at a mid-latitude city. International Journal of Climatology. 27 (9), 1243, 2007.

5. HART M.A., SAILOR D.J. Quantifying the influence of land-use and surface characteristics on spatial variability in the urban heat island. Theoretical and Applied Climatology. 95 (3), 397, 2009.

6. SVENSSON M.K. Sky view factor analysis - implications for urban air temperature differences. Meteorological Applications. 11 (3), 201, 2004.

7. YAN H., FAN S., GUO C., WU F., ZHANG N.,DONG L. Assessing the effects of landscape design parameters on intra-urban air temperature variability: The case of Beijing, China. Building and Environment. 76, 44, 2014.

8. ELIASSON I. Urban Geometry, surface temperature and air temperature. Energy and Buildings. 15 (1), 141, 1990.

9. BOURBIA F., AWBI H.B. Building cluster and shading in urban canyon for hot dry climate: Part 1: Air and surface temperature measurements. Renewable Energy. 29 (2), 249, 2004.

10. BOURBIA F., BOUCHERIBA F. Impact of street design on urban microclimate for semi arid climate (Constantine). Renewable Energy. 35 (2), 343, 2010.

11. CHEN L., NG E., AN X., REN C., LEE M., WANG U., HE Z. Sky view factor analysis of street canyons and its implications for daytime intra-urban air temperature differentials in high-rise, high-density urban areas of Hong Kong: a GIS-based simulation approach. International Journal of Climatology. 32 (1), 121, 2012.

12. YUPENG W., HASHEM A. Effect of Sky View Factor on Outdoor Temperature and Comfort in Montreal. Environmental Engineering Science. 31 (6), 272, 2014.

13. YANG F., QIAN F., LAU S.S.Y. Urban form and density as indicators for summertime outdoor ventilation potential: A case study on high-rise housing in Shanghai. Building and Environment. 70, 122, 2013.

14. DENG J.-Y.,WONG N.H. Impact of urban canyon geometries on outdoor thermal comfort in central business districts. Sustainable Cities and Society. 53, 101966, 2020.

15. BURIAN S.J., HAN W.S., BROWN M.J. Morphological analyses using 3D building databases: Houston, Texas. Department of Civil and Environmental Engineering, University of Utah, 2003.

16. YUAN C.,CHEN L. Mitigating urban heat island effects in high-density cities based on sky view factor and urban morphological understanding: a study of Hong Kong. Architectural Science Review. 54 (4), 305, 2011.

17. LI J., WANG J., WONG N.H. Urban Micro-climate Research in High Density Cities: Case Study in Nanjing. Procedia Engineering. 169, 88, 2016.

18. CHEN Y., WU J., YU K., WANG D. Evaluating the impact of the building density and height on the block surface temperature. Building and Environment. 168, 106493, 2020.

19. DENG J.-Y. Research on urban spatial form of cbd based on microclimate analysis - a case study of nanjing. 2018, Southeast University: Nanjing.

20. ZHOU R., ZHUANG R., HUANG C. Pattern evolution and formative mechanism of aging in China. Acta Geographica Sinica. 74 (10), 2163, 2019.

21. BRUSE M., FLEER H. Simulating surface-plant-air interactions inside urban environments with a three 
dimensional numerical model. Environmental Modelling \& Software. 13 (3), 373, 1998.

22. H I.U., A A.D., Performance evaluation of evaporative cooler using the Predictive Mean Vote (PMV) model. International Journal of Scientific and Technology Research. 2 (11), 272, 2013.

23. QIN Z. Cooling and humidifying effects and driving mechanisms of Beijjing Olympic Forest Park in summer. 2016, Beijing Forestry University: Beijing.

24. JAUREGUI E. Heat island development in Mexico City. Atmospheric Environment. 31 (22), 3821, 1997.

25. SALATA F., GOLASI I., DE LIETO VOLLARO R.,DE LIETO VOLLARO A., Urban microclimate and outdoor thermal comfort. A proper procedure to fit ENVI-met simulation outputs to experimental data. Sustainable Cities and Society. 26, 318, 2016.

26. ACERO J.A.,ARRIZABALAGA J. Evaluating the performance of ENVI-met model in diurnal cycles for different meteorological conditions. Theoretical and Applied Climatology. 131 (1), 455, 2018.

27. BURIAN S., RAM S., MADDULA K., VELUGUBANTLA S., BROWN M. Morphological analyses using 3D building databases: Albuquerque, New Mexico. LANL Report LA-UR-03-6198, 2002.

28. LOPEZ-CABEZA V.P., GALÁN-MARÍN C., RIVERAGÓMEZ C., ROA-FERNÁNDEZ J. Courtyard microclimate ENVI-met outputs deviation from the experimental data. Building and Environment. 144, 129, 2018.

29. SRIVANIT M., HOKAO K. The Influence of Urban Morphology Indicators on Summer Diurnal Range of Urban Climate in Bangkok Metropolitan Area, Thailand. The International Journals of Engineering and Sciences (IJENS). 11, 34, 2011.

30. WANG Z. Research on the Relationship between Urban 3D Space and Thermal Environment -A Case Study of Zhengzhou 2019, China University of Mining and Technology: Xuzhou.

31. OUALI K., EL HARROUNI K., ABIDI M.L., DIAB Y. Analysis of Open Urban Design as a tool for pedestrian thermal comfort enhancement in Moroccan climate. Journal of Building Engineering. 28, 101042, 2020.

32. LAI A., MAING M., NG E. Observational studies of mean radiant temperature across different outdoor spaces under shaded conditions in densely built environment. Building and Environment. 114, 397, 2017.

33. TAN C.L., WONG N.H., JUSUF S.K. Outdoor mean radiant temperature estimation in the tropical urban environment. Building and Environment. 64, 118, 2013.

34. LEE H., HOLST J., MAYER H. Modification of HumanBiometeorologically Significant Radiant Flux Densities by Shading as Local Method to Mitigate Heat Stress in Summer within Urban Street Canyons. 2013, 2013.

35. FARHADI H., FAIZI M., SANAIEIAN H. Mitigating the urban heat island in a residential area in Tehran: Investigating the role of vegetation, materials, and orientation of buildings. Sustainable Cities and Society. 46, 101448, 2019.

36. LAU K.K.-L., LINDBERG F., RAYNER D., THORSSON $\mathrm{S}$. The effect of urban geometry on mean radiant temperature under future climate change: a study of three European cities. International Journal of Biometeorology. 59 (7), 799, 2015

37. JAMEI E., RAJAGOPALAN P., SEYEDMAHMOUDIAN M., JAMEI Y. Review on the impact of urban geometry and pedestrian level greening on outdoor thermal comfort. Renewable and Sustainable Energy Reviews. 54, 1002, 2016.

38. ZHOU Y., SHI T., YUANMAN H., MIAO L. Landscape Pattern Optimization of Green Space Based on Numerical Simulation. City Planning Review. 40 (11), 167, 2017.

39. JOHANSSON E., SPANGENBERG J., GOUVÊA M.L., FREITAS E.D. Scale-integrated atmospheric simulations to assess thermal comfort in different urban tissues in the warm humid summer of São Paulo, Brazil. Urban Climate. 6, 24, 2013.

40. YANG J., SHI B., ZHENG Y., SHI Y., XIA G. Urban form and air pollution disperse: Key indexes and mitigation strategies. Sustainable Cities and Society. 57, 101955, 2020.

41. AHMADI VENHARI A., TENPIERIK M., TALEGHANI $M$. The role of sky view factor and urban street greenery in human thermal comfort and heat stress in a desert climate. Journal of Arid Environments. 166, 68, 2019.

42. HWANG R.-L., LIN T.-P., MATZARAKIS A. Seasonal effects of urban street shading on long-term outdoor thermal comfort. Building and Environment. 46 (4), 863, 2011.

43. YAHIA M.W., JOHANSSON E., THORSSON S., LINDBERG F., RASMUSSEN M.I. Effect of urban design on microclimate and thermal comfort outdoors in warmhumid Dar es Salaam, Tanzania. International Journal of Biometeorology. 62 (3), 373, 2018.

44. PERINI K., MAGLIOCCO A. Effects of vegetation, urban density, building height, and atmospheric conditions on local temperatures and thermal comfort. Urban Forestry \& Urban Greening. 13 (3), 495, 2014.

45. KAKON A.N., MISHIMA N., KOJIMA S. Simulation of the urban thermal comfort in a high density tropical city: Analysis of the proposed urban construction rules for Dhaka, Bangladesh. Building Simulation. 2 (4), 291, 2009. 